\title{
Trauma Care in Low- and Middle-Income Countries
}

\author{
Dhurka Shanthakumar, MBBS, MRCS ${ }^{1}$ Anna Payne, MBBS, MRCS ${ }^{2}$ Trish Leitch, LLM $^{3}$ \\ Maryam Alfa-Wali, FRCS, MEd, PhD²
}

${ }^{1}$ Department of Surgery, Whipps Cross Hospital, London, United Kingdom

2 Department of Surgery, Royal London Hospital, London, United Kingdom

${ }^{3}$ Department of Surgery, St George's Hospital, London, United Kingdom

Address for correspondence Maryam Alfa-Wali, FRCS, Med, PhD, Department of Surgery, Royal London Hospital, Whitechapel Road, London E1 1FR, United Kingdom (e-mail: m.alfa@doctors.org.uk).

Surg J (NY) 2021;7:e281-e285.

\begin{abstract}
Keywords

- trauma care

- trauma

- low- and middleincome countries

Background Trauma-related injury causes higher mortality than a combination of prevalent infectious diseases. Mortality secondary to trauma is higher in low- and middle-income countries (LMICs) than high-income countries. This review outlines common issues, and potential solutions for those issues, identified in trauma care in LMICs that contribute to poorer outcomes.

Methods A literature search was performed on PubMed and Google Scholar using the search terms "trauma," "injuries," and "developing countries." Articles conducted in a trauma setting in low-income countries (according to the World Bank classification) that discussed problems with management of trauma or consolidated treatment and educational solutions regarding trauma care were included.

Results Forty-five studies were included. The problem areas broadly identified with trauma care in LMICs were infrastructure, education, and operational measures. We provided some solutions to these areas including algorithm-driven patient management and use of technology that can be adopted in LMICs.

Conclusion Sustainable methods for the provision of trauma care are essential in LMICs. Improvements in infrastructure and education and training would produce a more robust health care system and likely a reduction in mortality in trauma-related injuries.
\end{abstract}

Injuries contribute to more deaths globally each year than the combination of HIV/AIDS, malaria, and tuberculosis. ${ }^{1}$ The global burden of injury is inversely proportional to income $e^{2,3}$; therefore, it is not surprising that low- and middle-income countries (LMICs) suffer the largest volume of injuries. Unfortunately, LMICs lack robust trauma and emergency surgery care. ${ }^{4}$ Trauma alone in LMICs is estimated to account for approximately 5 million annual global deaths. ${ }^{5-7}$ Globally, $\sim 50$ million individuals per year are left disabled after an injury. ${ }^{5}$ In Africa, 38 per 1,000 disability-adjusted life years are

received

July 28, 2020

accepted after revision

May 21, 2021
DOI https://doi.org/

$10.1055 / \mathrm{s}-0041-1732351$.

ISSN 2378-5128. reported compared with the global figure of 27 per 1,000.8,9 This may be due to war, assaults, and vehicle accidents that primarily affect a young population. This problem is compounded by lack of rehabilitation facilities. Often, even when these services exist, cost, or inadequate and unskilled staff inhibits access. Following traumatic injury, early presentation to hospital is unusual and diagnostic imaging remains scarce, thereby worsening the prognosis in LMICs. The main purpose of this review is to identify current issues and solutions surrounding provision of trauma care in LMICs. There were
(C) 2021. The Author(s).

This is an open access article published by Thieme under the terms of the Creative Commons Attribution License, permitting unrestricted use, distribution, and reproduction so long as the original work is properly cited. (https://creativecommons.org/licenses/by/4.0/)

Thieme Medical Publishers, Inc., 333 Seventh Avenue, 18th Floor, New York, NY 10001, USA 
three broadly identified challenging areas with trauma care in LMICs. These included infrastructure, education, and practical operational measures which are individually evaluated later.

\section{Methodology}

PubMed and Google Scholar were used to identify relevant articles using the search MeSH terms "trauma," "injuries," and "developing countries." Articles conducted in LMICs as defined by the World Bank classification, ${ }^{10}$ discussing problems with the management of trauma patients, or articles that consolidated treatment and educational solutions about trauma care, published between 1990 and 2020, were included. Of 4,432 search results, 45 articles were included. Review of relevant articles enabled the identification of three main areas for improvement in trauma care in LMICs, based on the domains identified by the World Health Organization (WHO) on surgical care systems strengthening. ${ }^{11}$

\section{Infrastructure}

Trauma care systems save lives in high-income countries (HICs). ${ }^{1}$ However, basic infrastructure is lacking in many LMICs. A key failure, with significant implications on public health in LMICs, is the lack of availability of basic amenities. Lack of water and electricity have a major impact on health care settings. ${ }^{12}$ Problems range from the simple provision of clean drinking water and sanitation facilities, to the inability to clean hospitals and autoclave surgical instruments. ${ }^{13}$ These problems inevitably have a role in the epidemiology of surgical site infections and hospital acquired infections in LMICs.

Funding for surgical care is limited or omitted completely in LMICs. ${ }^{14,15}$ This may be lacking as surgical treatments are deemed expensive, and not as cost effective compared with dealing with communicable disease management. Despite these preconceived ideas, surgery does occur at low cost, with rates from $\$ 40$ for a major surgical procedure in a lowvolume hospital to $\$ 300$ in a high-volume one. ${ }^{14}$ However, the standard of care provided is variable and difficult to measure, as is the definition of what constitutes major surgery.

There is a need for structurally safe buildings as research from the WHO has shown. ${ }^{11}$ Existing hospital buildings in LMICs are poorly maintained, with suboptimal management of clinical services. These should ideally be designed and constructed in a collaborative project with local and international architects and engineers. Materials could be sourced locally or used in combination with imported materials that would facilitate easy maintenance. Sustainability should be a focus, such as the use of solar panels for generating power to buildings, to help reduce longterm costs. Operating room facilities need to be updated. The provision of intensive care units would allow further management of the complex trauma patient and improve survival rates. Nevertheless, there needs to be a balance between resource availability and utilization to enable adequate and effective use of materials. This would facilitate comprehensive progress providing equipment and developing services that are beneficial in the LMIC setting, rather than just a drive to mirror HICs.
The poor condition of roads and vehicles, as well as nonadherence to road signs and speed limits, provides the formula for high numbers of road traffic injuries in LMICs. The causes are multifaceted and include poor road safety measures, inadequate roads, and human behavior. ${ }^{16}$ The majority of traumatic injuries in LMICs are caused by road traffic collisions (RTCs). The death rate following RTCs in lowincome countries (LICs) averages 27.5 deaths per 100,000 population compared with 8.3 per 100,000 in HICs. ${ }^{17}$ Procurement of engineers with expertise in road planning, traffic flow control, and maintenance of these facilities are necessary developments to minimize the injuries caused by RTCs. There is also a need to establish safety standards for vehicles and mandatory annual car safety inspections together with accountability measures as in HICs where drivers are traceable. The mean costs of injury in LMICs has been reported to vary between $\$ 14$ and $\$ 17,400$, with the costs of preventative interventions being slightly less with the use of speed bumps ${ }^{18}$ and other road safety measures. Other modes of transport, such as trains and ferries, could be used as alternative transport methods if proper training and safety measures were put in place, contributing to lowering the burden of RTC-related injuries. ${ }^{19}$

Infrastructural challenges and problems with resource distribution also limit the adequate management of trauma in LMICs. ${ }^{20}$ Organizational infrastructure such as fire services and safety measures may have an impact on the incidence and severity of burn injuries. Investment in the provision of adequate and affordable safe housing and living conditions to lessen overcrowding are essential considerations to be made on a national level in LMICs to avoid building accidents. Poor access to hospital services hinders injured patients from being treated promptly. Reasons for poor access include availability of transport vehicles, poor and unsafe traveling conditions, lack of nationalized systems to contact emergency services, and scarcity of emergency equipment. Prehospital care may be limited or not available, leading to more deaths outside the hospital in LMICs. ${ }^{2}$ Innovative strategies for providing prehospital care have been utilized in LMICs such as the training of first responders among the lay public as well as taxi drivers. ${ }^{21-23}$ Partnerships between governments and private sector companies form one potential strategy to address transportation problems. Change to the infrastructure in LMICs requires a radical approach that will include prevention strategies through injury surveillance, better prehospital and in-hospital care, as well as rehabilitation.

\section{Education}

Guidelines and protocols have been associated with decreased morbidity and mortality in HICs. ${ }^{24}$ Therefore, suitably developed guidelines need to be established in LMICs. Trauma educational programs in LMICs have been found to have a positive impact on practices and knowledge; however, translation into good patient outcomes is not described. ${ }^{25-27}$ The provision of courses is not the sole important aspect of educational progress. Retraining and revalidation are crucial to the acquisition and development of skills along with the 
consolidation of knowledge. Skills training and continuing professional development should be emphasized within health care settings in LMICs.

Basic life support (BLS) training of health care professionals is lacking in many LMICs. The principle of prompt resuscitation needs to be embedded into the acute care of trauma patients, with training starting at undergraduate level. Training for BLS is relatively simple to set up and, as the equipment is reusable, annual recertification is easy to establish, as staff can be trained in-house. ${ }^{28}$ The trauma management courses in HICs should be specifically tailored for use in LMICs. Low-cost alternatives to the Advanced Trauma Life Support (ATLS) courses have been developed, such as the Trauma Evaluation and Management course. ${ }^{29}$ Equivalent courses to the Pre-Hospital Life Support course, tailored in an affordable manner, can be built into preexisting systems. In Nigeria and Ghana, trauma education courses have been developed from the ATLS course with the materials and infrastructure adapted to suit the population. ${ }^{30,31}$ However, the continued practice and dispersion of these courses is yet proven, and evaluation in low-resource settings remains a continuous challenge.

The lack of adequate training, low salaries, and the brain drain of medical professionals to HICs contribute to the staff shortages in LMICs. ${ }^{8}$ Several African countries have a high mortality rate associated with general anesthesia. ${ }^{32}$ Some countries have only one or two trained anesthetists, with the remaining anesthetic cover being provided by nurses. Secondment of well-trained anesthetists from a global pool to sustain education, program development and training may be the way forward to counteract this issue. Countries such as Malawi and Mozambique combat medical personnel shortages by training nurses and medical assistants to perform surgical procedures ${ }^{33,34}$; however, the data on outcomes are scarce. The concept of multidisciplinary team working is deep-rooted in HICs. This concept should be encouraged in LMICs, via colearning and simulation teaching, to establish the provision of coordinated care. This could be done at negligible cost to institutions in LMICs; thus, enhancing trauma team training, understanding of criteria for trauma calls, and improved triaging; as emergency departments are mostly nurse-led in LMICs.

Public health campaigns would be helpful in injury prevention. Campaigns and information sheets should be implemented in written and pictorial formats, and should be easy to understand without the need for literacy. Rehabilitated trauma patients should be advocates for education about safety, through the implementation of community collaborations with the understanding of legislation and law enforcement.

\section{Practical and Operational Measures}

The management of the critically ill surgical patient requires prompt diagnosis of the injuries. The lack of diagnostic imaging modalities such as computed tomography is apparent in LMICs. ${ }^{35}$ In some LMICs, radiographs are still processed using traditional techniques, with the drying of the films on washing lines in the sunshine. This is a slow and unsustainable process in the management of a trauma patient where time is of the essence. The type of traumarelated injury varies from neurological, musculoskeletal, visceral trauma and burns. Establishing simple trauma scoring systems that do not require complex data on anatomical injuries is beneficial, ${ }^{36}$ such as the Kampala trauma score in Uganda. ${ }^{37}$

Most LMICs have limited staff in terms of both health care professionals and supporting technical staff, such as laboratory staff and therapists. ${ }^{38,39}$ It is however acknowledged that nonmedical personnel provide the surgical and trauma care in low-resource settings. ${ }^{40}$ Algorithms for the initial assessment and reassessment of the critically ill surgical patient are essential. Setting realistic physical thresholds for trauma team activation in LMICs is vital for human resource planning. Work force planning is paramount in the future development of any country. A model of a fee-for-service, rather than salaried positions, could be tried by governments to try and minimize the brain drain of health care professionals from LMICs going to HICs.

There is a stark difference between LMICs and HICs with regard to the use of information technology and communications in the health care setting. The lack of universal availability of computers in public hospitals but the availability of mobile phones makes them amenable to use in hospitals. Trials using mobile technology as a tool to implement electronic-based health records have been positive. For example, the electronic Trauma Health Record (eTHR) made the use of tablet-based health records. This was both designed and tested in low-income settings. The eTHR included features to upload trauma admission data in terms of demographics, diagnosis, treatments, complications, and follow-up plans. ${ }^{41}$ Such electronic registries enable accurate auditing and documentation of information regarding injury, allowing future improvement of services.

The benefit of mobile phone technology is still vastly underutilized and would be a useful source for obtaining trauma data. Remarkably, a high proportion of individuals in LMICs have mobile phones, thus can be used to enable prehospital communication and improve preparedness for hospital staff. Telemedicine has previously been applied to good use, for example, between the United States and Armenia immediately after disaster situations, which improved diagnostic accuracy and patient care in the immediate phase. ${ }^{42}$

\section{Discussion}

This article highlights some of the problems of trauma care provision in LMICs and offers possible solutions, which are by no means exhaustive. It is estimated that 2 million deaths per year could be prevented through the provision of adequate trauma care in LMICs. ${ }^{43}$ The global socioeconomic impact of surgical conditions in terms of the number of days lost to working, percentage of unemployment, and the effect on families is likely to be underestimated. Governments of LMICs have an integral role to play to allow better provision of trauma care. However, data on acute and traumatic 
surgical conditions are scarce, therefore, making it difficult to influence governments on public health policies, and provision of both appropriate amenities and clinical resources. Economic evidence rather than speculations of economic impact from injuries needs to be presented to stakeholders before change can truly be made in low-resource settings.

Globalization comes at a cost. The coupling of cheaper vehicles and growing populations, with the lack of health care development and systems, fuel marginalization. Adequate planning of health systems in LMICs, in a low-cost manner, is essential for strengthening of services. A solid infrastructure will contribute to better patient care. There is an inherent lack of road traffic injury surveillance systems in LMICs. ${ }^{16}$ Governments need to focus on establishing legislation and provision of adequate policing services which provide accountability when laws are broken.

Cost-effective trauma systems ${ }^{4}$ that are contextualized to low-resource settings need to be further developed, as the "one size fits all" approach is not always constructive. Nevertheless, beyond the goals set by the $\mathrm{WHO},{ }^{44}$ there should be a drive originating within nations through their health ministries to understand the short- and long-term benefits of providing safe and effective health care. Challenges will exist when changes to cultural norms are being implemented. Health economists should be consulted to see what funding is required for surgical conditions, and whether this puts strain on health budgets. Sustainability in health care reforms in combination with appropriate policies can make a robust health care system. Clinical governance strategies such as quality improvement and auditing are valuable tools which satisfy stakeholders and must be encouraged in LMIC health care systems. Additionally, corruption in global health agendas, and its impact on health and food security, is yet to be fully addressed.

Education throughout the training of health care professionals is paramount to obtain and maintain a level of goodquality trauma care. Traditionally, trauma and emergency surgery are not specifically taught in medical schools. However, this is gradually changing. For example, in parts of the United Kingdom, emergency surgery placements now exist for medical students. The concept of joint ventures between hospitals in LICs and HICs to improve education, training, and research would be advantageous. This is exemplified by the collaborative work between East, Central, and Southern African countries and Oxford University. ${ }^{45}$ This partnership has enabled training in trauma management in nine countries in Africa with primary courses being delivered by the United Kingdom instructors and subsequently by local faculty. ${ }^{45}$

Trauma registries are well developed and maintained in HICs. They play a significant role in the evaluation of patient care and assessing demographics for education. ${ }^{46,47}$ Social media platforms, mobile apps, and radios are effective means of communication in LMICs for education and could be used to harness data by encouraging members of the public to report injuries. Nevertheless, these data collecting systems have to be monitored for to minimize incorrect and duplication of data. Technology in the form of mobile phones could also aid prehospital care and remote follow-up of patients.

\section{Conclusion}

We acknowledge this review is limited by not being a systematic review of trauma in LMICs. However, it gives a synopsis of the key problems and provides possible solutions both novel and previously described in the literature. This review has delineated a range of economic and social strategies that are necessary for the provision of better trauma care in LMICs. Improvements in infrastructure along with education and training would likely lead to reduced morbidity and mortality among trauma patients in LMICs. This article also highlights a lack of research on trauma care in LMICs, more of which is needed for policy design and change.

\section{Funding \\ None.}

Conflict of Interest

None declared.

\section{References}

1 Reynolds TA, Stewart B, Drewett I, et al. The impact of trauma care systems in low- and middle-income countries. Annu Rev Public Health 2017;38:507-532

2 Mock CN, Jurkovich GJ, nii-Amon-Kotei D, Arreola-Risa C, Maier RV. Trauma mortality patterns in three nations at different economic levels: implications for global trauma system development. J Trauma 1998;44(05):804-812, discussion 812-814

3 Ozgediz D, Jamison D, Cherian M, McQueen K. The burden of surgical conditions and access to surgical care in low- and middleincome countries. Bull World Health Organ 2008;86(08):646-647

4 Stelfox HT, Joshipura M, Chadbunchachai W, et al. Trauma quality improvement in low and middle income countries of the AsiaPacific region: a mixed methods study. World J Surg 2012;36(08): 1978-1992

5 Murray CJ, Barber RM, Foreman KJ, et al; GBD 2013 DALYs and HALE Collaborators. Global, regional, and national disabilityadjusted life years (DALYs) for 306 diseases and injuries and healthy life expectancy (HALE) for 188 countries, 1990-2013: quantifying the epidemiological transition. Lancet 2015;386 (10009):2145-2191

6 Mock C, Abantanga F, Goosen J, Joshipura M, Juillard C. Strengthening care of injured children globally. Bull World Health Organ 2009;87(05):382-389

7 Gosselin RA, Spiegel DA, Coughlin R, Zirkle LG. Injuries: the neglected burden in developing countries. Bull World Health Organ 2009;87(04):246-246a

8 Sakran JV, Greer SE, Werlin E, McCunn M. Care of the injured worldwide: trauma still the neglected disease of modern society. Scand J Trauma Resusc Emerg Med 2012;20:64

9 Murray CJ, Vos T, Lozano R, et al. Disability-adjusted life years (DALYs) for 291 diseases and injuries in 21 regions, 1990-2010: a systematic analysis for the Global Burden of Disease Study 2010. Lancet 2012;380(9859):2197-2223

10 The World Bank. Classifying countries by income. Published 20019. Accessed December 1, 2020 at: https://datatopics. worldbank.org/world-development-indicators/stories/the-classification-of-countries-by-income.html

11 Haider A, Scott JW, Gause CD, et al. Development of a unifying target and consensus indicators for global surgical systems strengthening: proposed by the Global Alliance for Surgery, Obstetric, Trauma, and Anaesthesia Care (The G4 Alliance). World J Surg 2017;41(10):2426-2434 
12 Anand M. Health status and health care services in Uttar Pradesh and Bihar: a comparative study. Indian J Public Health 2014;58 (03):174-179

13 de Snyder VN, Friel S, Fotso JC, et al. Social conditions and urban health inequities: realities, challenges and opportunities to transform the urban landscape through research and action. J Urban Health 2011;88(06):1183-1193

14 Kruk ME, Wladis A, Mbembati N, et al. Human resource and funding constraints for essential surgery in district hospitals in Africa: a retrospective cross-sectional survey. PLoS Med 2010;7 (03):e1000242

15 Mock C, Nguyen S, Quansah R, Arreola-Risa C, Viradia R, Joshipura M. Evaluation of trauma care capabilities in four countries using the WHO-IATSIC guidelines for essential trauma care. World J Surg 2006;30(06):946-956

16 Mock C, Kobusingye O, Anh V, Afukaar F, Arreola-Risa C. Human resources for the control of road traffic injury. Bull World Health Organ 2005;83(04):294-300

17 WHO. Global status report on road safety. 2018

18 Wesson HK, Boikhutso N, Bachani AM, Hofman KJ, Hyder AA. The cost of injury and trauma care in low- and middle-income countries: a review of economic evidence. Health Policy Plan 2014;29(06):795-808

19 Borowy I. Road traffic injuries: social change and development. Med Hist 2013;57(01):108-138

20 Petroze RT, Byiringiro JC, Ntakiyiruta G, et al. Can focused trauma education initiatives reduce mortality or improve resource utilization in a low-resource setting? World J Surg 2015;39(04):926-933

21 Jayaraman S, Mabweijano JR, Lipnick MS, et al. Current patterns of prehospital trauma care in Kampala, Uganda and the feasibility of a layfirst-responder training program. World J Surg 2009;33(12):2512-2521

22 Tiska MA, Adu-Ampofo M, Boakye G, Tuuli L, Mock CN. A model of prehospital trauma training for lay persons devised in Africa. Emerg Med J 2004;21(02):237-239

23 Geduld H, Wallis L. Taxi driver training in Madagascar: the first step in developing a functioning prehospital emergency care system. Emerg Med J 2011;28(09):794-796

24 Kesinger MR, Puyana JC, Rubiano AM. Improving trauma care in low- and middle-income countries by implementing a standardized trauma protocol. World J Surg 2014;38(08):1869-1874

25 Ali J, Adam R, Butler AK, et al. Trauma outcome improves following the Advanced Trauma Life Support program in a developing country. J Trauma 1993;34(06):890-898, discussion 898-899

26 Mock C, Kobusingye O, Joshipura M, Nguyen S, Arreola-Risa C. Strengthening trauma and critical care globally. Curr Opin Crit Care 2005;11(06):568-575

27 Mock CN, nii-Amon-Kotei D, Maier RV. Low utilization of formal medical services by injured persons in a developing nation: health service data underestimate the importance of trauma. J Trauma 1997;42(03):504-511, discussion 511-513

28 Mohammed Z, Arafa A, Saleh Y, et al. Knowledge of and attitudes towards cardiopulmonary resuscitation among junior doctors and medical students in Upper Egypt: cross-sectional study. Int J Emerg Med 2020;13(01):19

29 Kurdin A, Caines A, Boone D, Furey A. TEAM: a low-cost alternative to ATLS for providing trauma care teaching in Haiti. J Surg Educ 2018;75(02):377-382
30 Tortella BJ, Swan KG, Donahoo JS, et al. Trauma life support education: a didactic and caprine laboratory course for Nigerian physicians. Injury 1996;27(05):329-331

31 Mock CN, Quansah R, Addae-Mensah L, Donkor P. The development of continuing education for trauma care in an African nation. Injury 2005;36(06):725-732

32 Walker IA, Wilson IH. Anaesthesia in developing countries-a risk for patients. Lancet 2008;371(9617):968-969

33 Lavy C, Tindall A, Steinlechner C, Mkandawire N, Chimangeni S. Surgery in Malawi - a national survey of activity in rural and urban hospitals. Ann R Coll Surg Engl 2007;89(07):722-724

34 Vaz F, Bergström S, Vaz MdaL, Langa J, Bugalho A. Training medical assistants for surgery. Bull World Health Organ 1999;77(08): 688-691

35 Ngoya PS, Muhogora WE, Pitcher RD. Defining the diagnostic divide: an analysis of registered radiological equipment resources in a low-income African country. Pan Afr Med J 2016;25:99

36 Laytin AD, Dicker RA, Gerdin M, et al. Comparing traditional and novel injury scoring systems in a US level-I trauma center: an opportunity for improved injury surveillance in low- and middleincome countries. J Surg Res 2017;215:60-66

37 Weeks SR, Juillard CJ, Monono ME, et al. Is the Kampala trauma score an effective predictor of mortality in low-resource settings? A comparison of multiple trauma severity scores. World J Surg 2014;38(08):1905-1911

38 Stewart BT, Quansah R, Gyedu A, Ankomah J, Donkor P, Mock C. Strategic assessment of trauma care capacity in Ghana. World J Surg 2015;39(10):2428-2440

39 Hadler RA, Chawla S, Stewart BT, McCunn MC, Kushner AL. Anesthesia care capacity at health facilities in 22 low- and middle-income countries. World J Surg 2016;40(05):1025-1033

40 Ashengo T, Skeels A, Hurwitz EJH, Thuo E, Sanghvi H. Bridging the human resource gap in surgical and anesthesia care in lowresource countries: a review of the task sharing literature. Hum Resour Health 2017;15(01):77

41 Zargaran E, Schuurman N, Nicol AJ, et al. The electronic Trauma Health Record: design and usability of a novel tablet-based tool for trauma care and injury surveillance in low resource settings. J Am Coll Surg 2014;218(01):41-50

42 Houtchens BA, Clemmer TP, Holloway HC, et al. Telemedicine and international disaster response. Medical consultation to Armenia and Russia via a Telemedicine Spacebridge. Prehosp Disaster Med 1993;8(01):57-66

43 Mock C, Joshipura M, Arreola-Risa C, Quansah R. An estimate of the number of lives that could be saved through improvements in trauma care globally. World J Surg 2012;36(05):959-963

44 WHO. Guidelines for essential trauma care. 2004

45 Peter NA, Pandit H, Le G, Nduhiu M, Moro E, Lavy C. Delivering a sustainable trauma management training programme tailored for low-resource settings in East, Central and Southern African countries using a cascading course model. Injury 2016;47(05):1128-1134

46 St-Louis E, Paradis T, Landry T, Poenaru D. Factors contributing to successful trauma registry implementation in low- and middleincome countries: a systematic review. Injury 2018;49(12): $2100-2110$

47 Moore L, Clark DE. The value of trauma registries. Injury 2008;39 (06):686-695 